\title{
Spectrum of Magnetic Resonance Imaging Findings in Fungal Infections of Brain
}

\author{
Kamini Gupta ${ }^{1}$, Avik Banerjee ${ }^{2}$, Kavita Saggar ${ }^{3}$ \\ ${ }^{1}$ Associate Professor, Department of Radiodiagnosis, ${ }^{2}$ Resident, Department of Radiodiagnosis, ${ }^{3}$ Professor and Head, \\ Department of Rdiodiagnosis, Dayanand Medical College and Hospital, Ludhiana, Punjab, India.
}

Corresponding author: Dr. Kamini Gupta, C/o Profile Clinic, 47-B, Tagore Nagar, Ludhiana, 141001, India

DOI: $10.21276 /$ ijcmsr.2018.3.2.33

How to cite this article: Kamini Gupta, Avik Banerjee, Kavita Saggar. Spectrum of magnetic resonance imaging findings in fungal infections of brain. International Journal of Contemporary Medicine Surgery and Radiology. 2018;3(2):B137-B142.

\section{A B S T R A C T}

Introduction: Fungal infections of the brain are common and fatal if not diagnosed and treated timely. Despite the general lack of diagnostic specificity, certain findings are more commonly associated with particular fungal pathogens. We, in the present series, evaluate the magnetic resonance imaging (MRI) features and correlate the neuroradiological diagnosis with the nature of fungal pathogens. Study aimed to analyze MRI features in fungal infections of brain and correlate radiological diagnosis with clinical and histopathological diagnosis.

Materials and Methods: This study was conducted on patients with suspected / previously diagnosed cases of CNS infections referred to the department of Radiodiagnosis at Dayanand Medical College, Ludhiana over one year. MRI was performed on MAGNETOM Avanto 18 Channel 1.5 Tesla TM MR Machine by Siemens India Ltd.MRI protocol consisted of the Turbo spin echo (TSE) T2W sequence, Spin echo (SE) T1W sequence, FLAIR, GRE, DW and Post-gad T1W sequences.

Results: In the present study, we found that fungal infections occur more commonly in the middle and old age group with some predisposing risk factor or with primary focus elsewhere. Fungal cerebral abscesses may have central restricted diffusion, apart from the well-recognized pattern, with restriction in the wall and intrapillary projections. Oculorhinocerebral pathology with bone destruction usually has fungal etiology.

Conclusion: Cerebral infarcts in immunocompromised individuals, with or without significant meningeal enhancement, may be due to cryptococcosis. Aspergillosis may manifest as an extradural lesion mimicking a meningioma or intraaxial butterfly glioma.

Key words: Aspergillosis, Diffusion Restriction, Fungal Abscess, Magnetic Resonance Imaging, Mucormycosis

\section{INTRODUCTION}

Fungal infections of the central nervous system (CNS) are rare although relatively more frequent in the tropics. These occur either in immunocompromised patients or are generally secondary in nature, with the primary focus elsewhere in the body. The region of the brain affected largely depends on the size of the fungus, which in turn decides the site of lodgment in the brain. Smaller fungi, such as Candida and Cryptococcus, can reach microcirculation causing meningitis and micro abscesses. The larger ones, such as Aspergillus and Mucor, occlude major arteries resulting in large areas of infarction and subsequently abscesses. Most people being immunocompromised, lack cellular reactions and thus neuroimaging findings are often nonspecific. Thus correct diagnosis is based on the combined approach of imaging, clinical settings, and cerebrospinal fluid (CSF) findings. ${ }^{1}$

We present a study of fungal infections of brain, where the clinical, biochemical and neuroimaging findings were evaluated and correlated to determine the characteristics, extent and complications of the disease.

Study aimed at analysis of magnetic resonance imaging
(MRI) findings in the fungal infections of the brain and to correlate the neuroradiological diagnosis with CSF/ biochemical/ histopathological or microbiological analysis.

\section{MATERIAL AND METHODS}

This study was conducted on patients with suspected / previously diagnosed cases of CNS infections referred to the department of Radiodiagnosis at Dayanand Medical College, Ludhiana. Informed consent was obtained from all the subjects. The detailed clinical history regarding the onset of symptoms and clinical progression of the disease process was taken along with special consideration to neurological examination. The spectrum of MRI findings was recorded.

This was a longitudinal, prospective study over a period of one year. MRI was performed on MAGNETOM Avanto 18 Channel 1.5 Tesla TM MR Machine by Siemens India Ltd. After taking localizers in all three planes, the MRI protocol consisted of the Turbo spin echo (TSE) T2W sequence, Spin echo (SE) T1W sequence, FLAIR-Fluid attenuated inversion recovery sequence and GRE sequence in axial plane. This was followed by FLAIR sequence in coronal plane and 


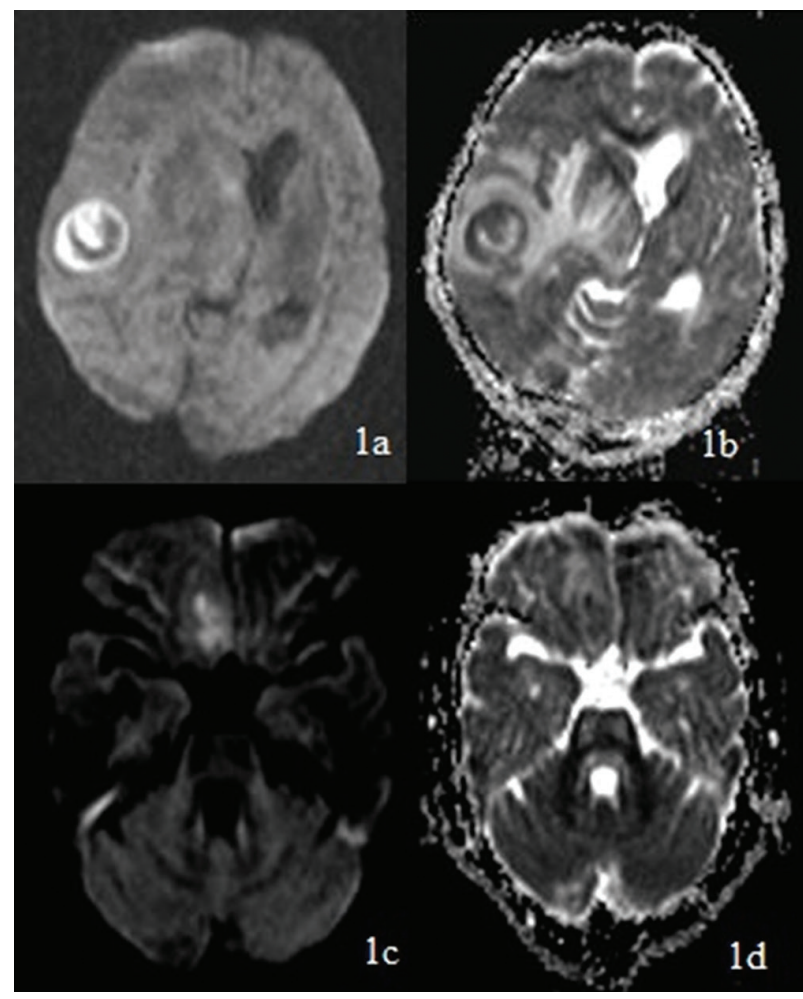

Figure-1: A case of fungal abscess shows diffusion restriction in the wall and intracavitory projections on diffusion weighted and ADC images in (a) and (b), respectively. Another case of fungal cerebritis due to Penicillium shows patchy diffusion restriction in the central part in (c) and (d).

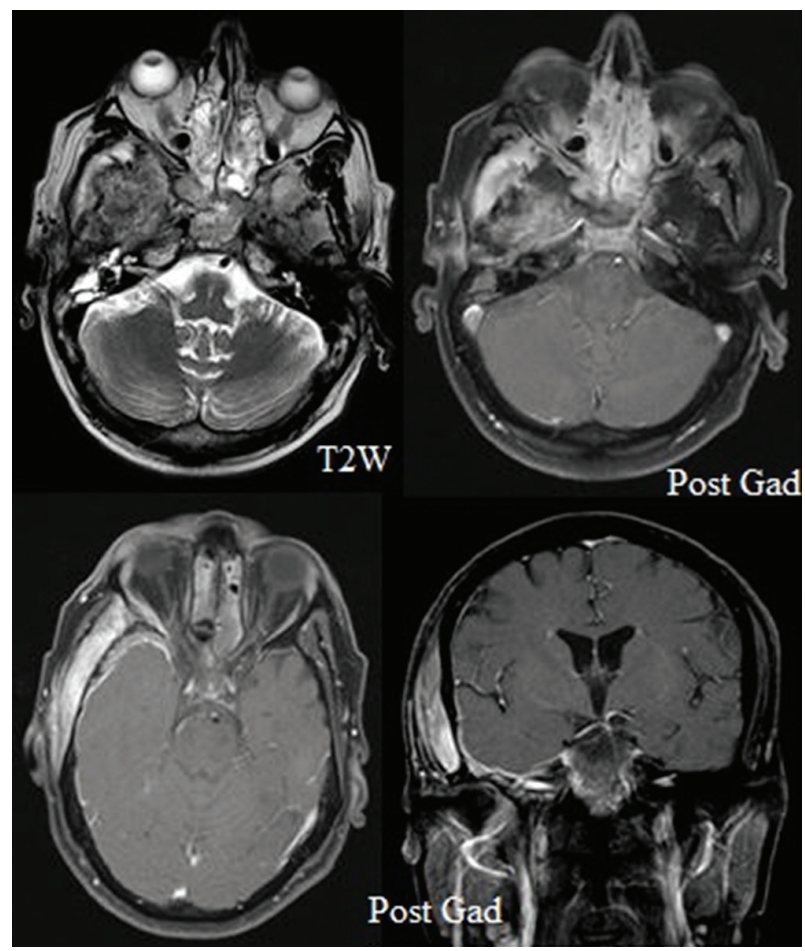

Figure-2: A 45-year-old male with mucormycosis; axial T2weighted image shows heterogeneously hypointense signal in the sphenoid sinus and temporal lobe with expansion and marrow infiltration of the temporal bone. Also note bilateral ethmoid sinusitis and mastoiditis. Postcontrast images show marked enhancement of these areas with overlying pachymeningeal enhancement.

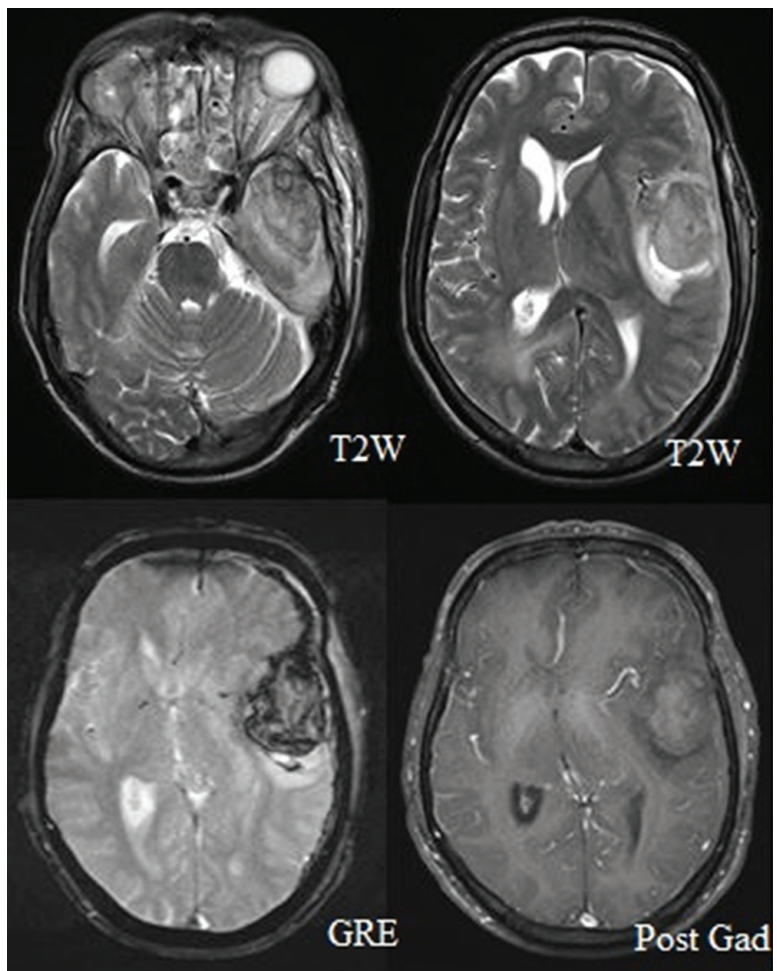

Figure-3: A 60-year-old male with mucormycosis involving ethmoid and sphenoid sinuses shows a T2-weighted iso to hyperintense lesion with peripheral edema and subdural collection in left temporoparietal region. It shows marked blooming on GRE image to suggest hemorrhagic nature. Post-gadolinium image shows dural enhancement.

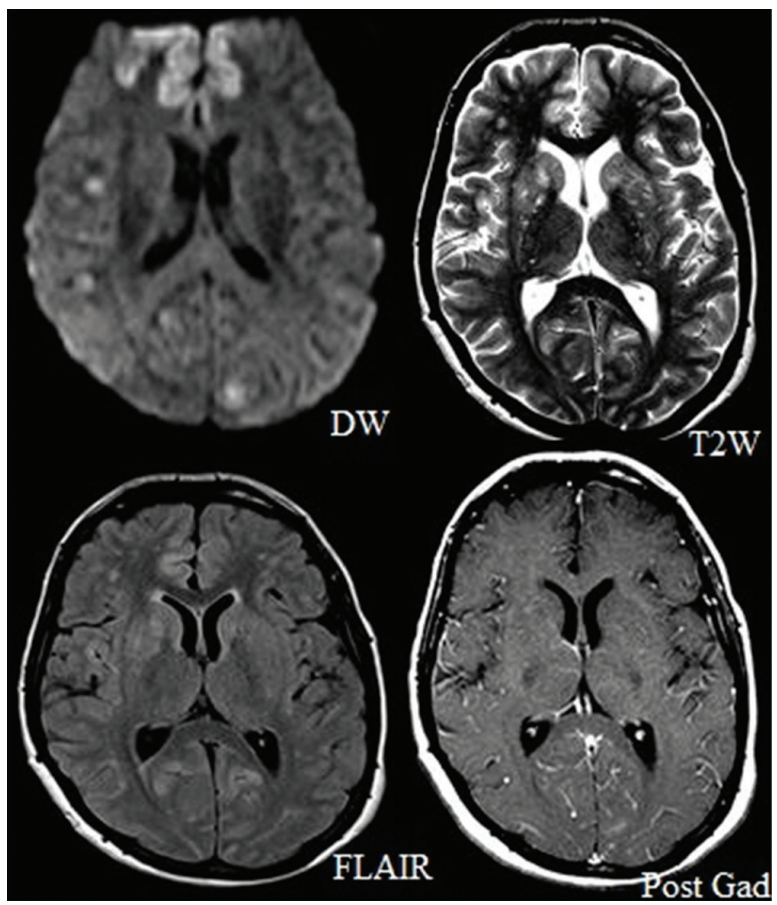

Figure-4:A 29-year-old HIV reactive male with cryptococcal meningoencephalitis; axial diffusion weighted image shows restriction in cingulate gyri and multifocal areas in the right parietal and left occipital regions. T2-weighted and FLAIR images shows hyperintense signal in these areas as well as in the bilateral basal ganglia. Post gadolinium image shows leptomeningeal enhancement in occipital lobes. 


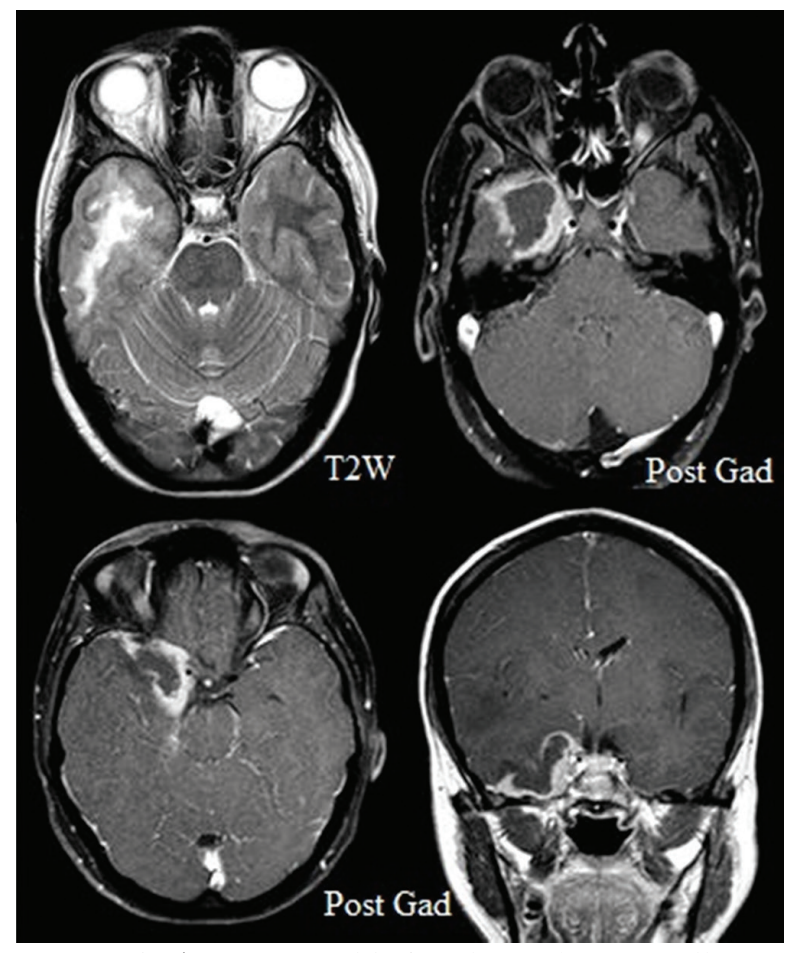

Figure-5: A 32-year-old female with aspergillosis; axial T2-weighted image shows a hyperintense lesion in the anteromedial aspect of right temporal lobe with underlying white matter edema. Post gadolinium images show thick plaque-like homogenous enhancement in these extraaxial areas with encasement of cavernous segment of the right internal carotid artery, which is attenuated in caliber.

T2W sequence in sagittal plane. Contrast enhanced T1W sequence and diffusion weighted and ADC imaging were performed in every subject. The MR imaging differentials was correlated with the clinical differentials based on csf/ biochemical/ microbiological/ histopathological analysis.

\section{RESULTS}

We analyzed 10 cases that were diagnosed as intracranial fungal infections. Three were females and seven were males. The age group of the patients ranged from 24 to 65 years with a median age of 45 years. Most of the patients had either an underlying immunosuppression or had fungal sinusitis, which predisposed them to the rhino cerebral infection. The most common chief presenting complaint was headache present in 6 patients. Fever and abnormal movements/seizure were seen in 4 patients. Vomiting and altered sensorium was found in 2 patients whereas one patient presented with focal weakness. Each of these clinical features was seen in isolation or in combination with one another.

The Glassgow Coma Scale score ranged from 15 to 10 with a median score of 14 . Two patients presented with generalized tonic clonic seizures, whereas 1 had cerebellar symptoms and 1 had bilateral sixth nerve palsy.

CSF examination was done in seven patients. In three patients, straightway a tissue sample was procured. In the 7 patients analyzed, the number of cells per tap ranged from 34 to 80 with an average value of 48 . The number of lymphocytes per tap ranged from 23 to 80 with a median value of 48 . The number of neutrophills per tap ranged from 0 to 11 with an

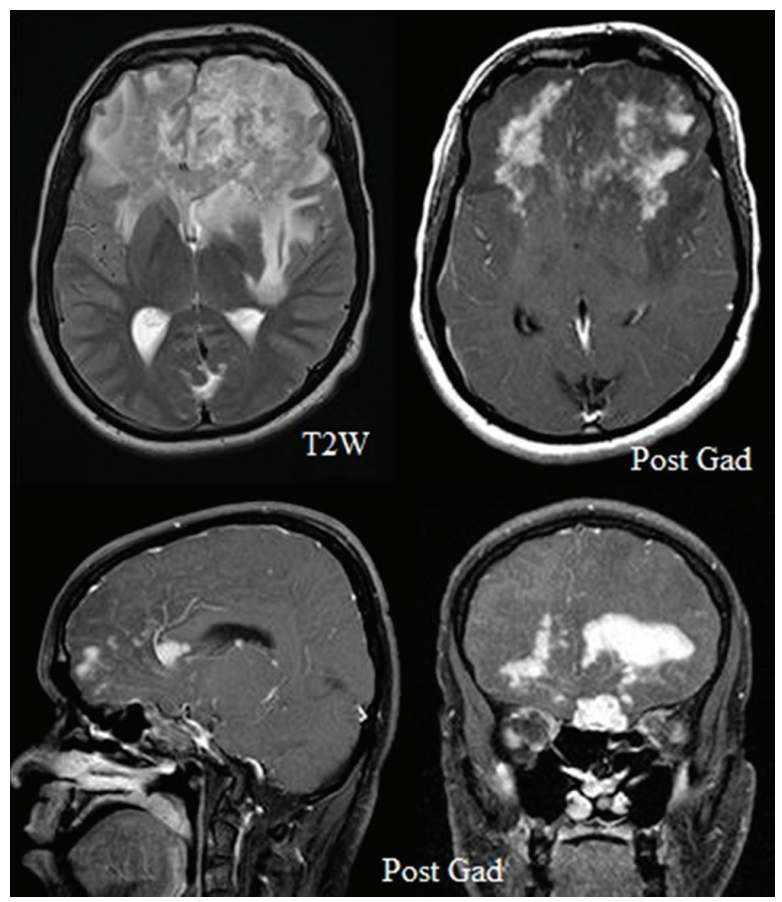

Figure-6: A 24-year-old male with aspergillosis; axial T2W image shows a heterogeneously hyperintense lesion in bifrontal lobes also involving the corpus callosum with extensive white matter oedema. Post gadolinium images show significant patchy enhancement in these areas with left frontal leptomeningeal enhancement.

average value of 5. The glucose level ranged from 24 to 79 $[\mathrm{mg} / \mathrm{dl}]$ with an average value of 39 . The protein level ranged from 112 to $680[\mathrm{mg} / \mathrm{dl}]$ with an average value of 250 .

Histopathological confirmation was available in all the cases. $30 \%$ of the cases were due to mucormycosis, $20 \%$ due to aspergillosis, $20 \%$ due to cryptococcosis, and $10 \%$ were due to candidiasis, penicillium and pheohyphomycosis each. (Table 1)

In addition, the MRI patterns of various fungal infections were evaluated. (Table 2)

\section{DISCUSSION}

We analyzed the neuroimaging features of 10 cases of intracranial fungal infections. Mucormycosis, Aspergillosis, and Cryptococcosis were the most common CNS fungal infections in a tertiary care hospital like ours. Sethi et $\mathrm{al}^{2}$ in 2012, also found the same spectrum, prevalence, and predisposing factors.

Two patients in our study showed peripherally enhancing abscess with intracavitatory projections (Figure 1) and diffusion restriction both in the walls and in the projections. (Figure 2)

This typical nature of a fungal abscess in our study matches the parameters of the study conducted by Luthra et al. ${ }^{3}$ They found that fungal abscesses showed irregular walls (lobulated $4 / 8$, crenated 4/8) with intracavitary projections (8/8). In the fungal abscesses, the wall and projections showed low apparent diffusion co-efficient (ADC) (8/8); however, the cavity itself showed high ADC (8/8).

This however may always not be true, as evidenced in our study. One case of abscess due to Candida species showed 


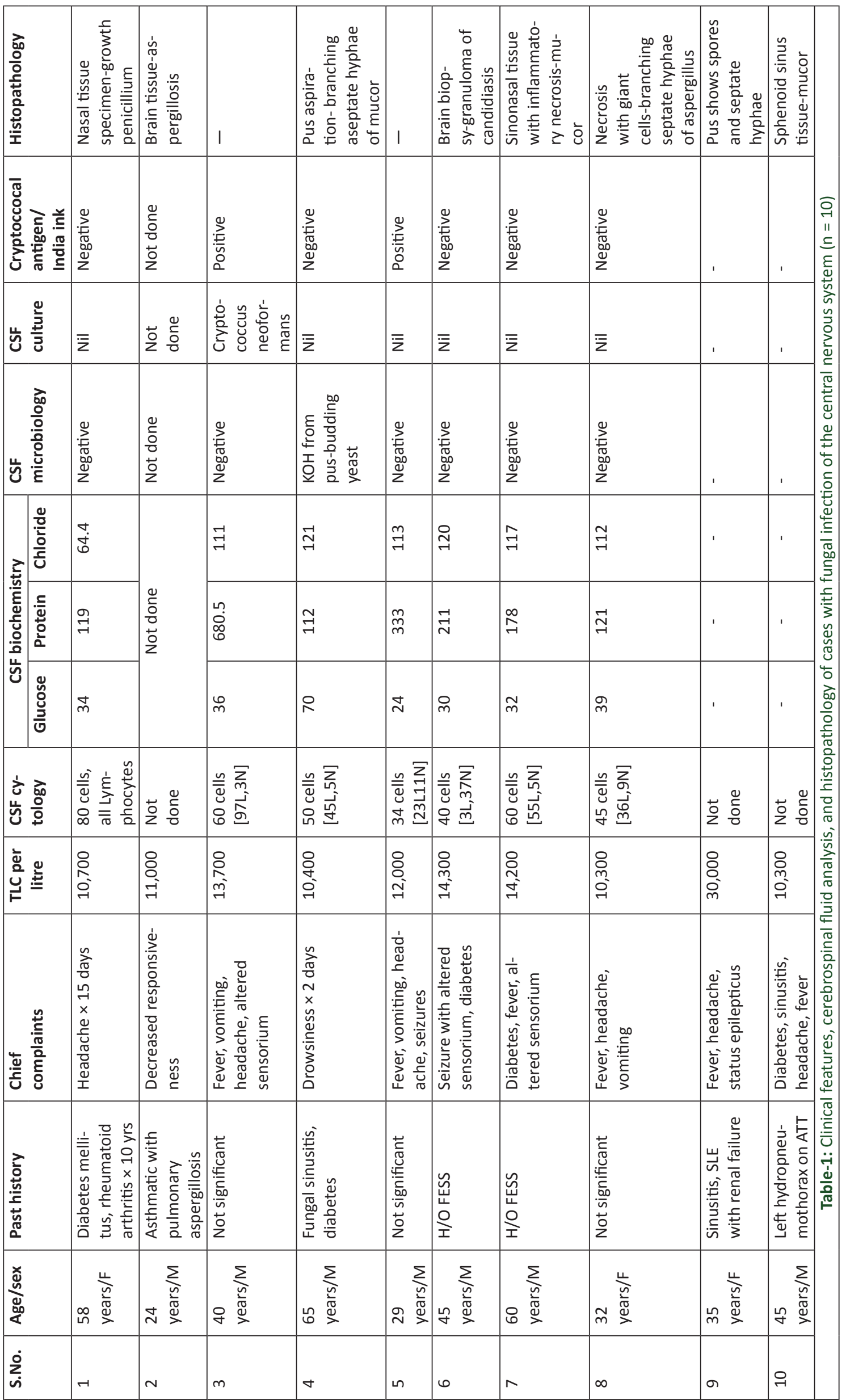




\begin{tabular}{|c|c|c|c|c|}
\hline $\begin{array}{l}\text { S. } \\
\text { No. }\end{array}$ & MRI findings & MRI differentials & Treatment and outcome & Final diagnosis \\
\hline 1 & $\begin{array}{l}\text { Sinusitis with cerebritis/frontal ab- } \\
\text { scess and pachymeningeal enhance- } \\
\text { ment }\end{array}$ & $\begin{array}{l}\text { Pyogenic/fungal } \\
\text { infection }\end{array}$ & $\begin{array}{l}\text { FESS with septoplasty } \\
\text { Ethmoid and sphenid } \\
\text { cavity full of pus and } \\
\text { Fungal material } \\
\text { Growth showed } \\
\text { penicillium }\end{array}$ & $\begin{array}{l}\text { Fungal sinusitis with frontal } \\
\text { abscess and meningitis }\end{array}$ \\
\hline 2 & $\begin{array}{l}\text { Large heterogenously enhancing } \\
\text { bifrontal lesion, also involving corpus } \\
\text { callosum }\end{array}$ & $\begin{array}{l}\text { Butterfly } \\
\text { gioma, lymphoma }\end{array}$ & $\begin{array}{l}\text { Brain biopsy } \\
\text { Put on antifungals }\end{array}$ & Aspergillosis \\
\hline 3 & $\begin{array}{l}\text { Multiple bilateral cerebral infarcts } \\
\text { with meningitis }\end{array}$ & - & Oral and I/V antifungals & Cryptococcal meningitis \\
\hline 4 & $\begin{array}{l}\text { Large bifrontal abcesses with diffu- } \\
\text { sion restriction in walls and intrapap- } \\
\text { illary projections }\end{array}$ & - & Oral and $\mathrm{I} / \mathrm{V}$ antifungals & Mucormycosis \\
\hline 5 & $\begin{array}{l}\text { Meningitis with bilateral cingulate } \\
\text { gyri and basal ganglia encephalitis }\end{array}$ & Meningoencephalitis & $\mathrm{I} / \mathrm{V}$ antifungals & $\begin{array}{l}\text { HIV positive with cryptococcal } \\
\text { meningitis }\end{array}$ \\
\hline 6 & $\begin{array}{l}\text { Thick-walled left frontal abscess with } \\
\text { multiple nodular cerebral lesions }\end{array}$ & Fungal/bacterial & $\begin{array}{l}\text { Operated, oral and I/V } \\
\text { antifungals, steroids }\end{array}$ & Fungal granuloma- candidiasis \\
\hline 7 & $\begin{array}{l}\text { Fungal sinusitis with orbital cellulitis; } \\
\text { biparietal and left temporal hemor- } \\
\text { rhagic cerebritis with SDH }\end{array}$ & - & $\begin{array}{l}\text { Operated, oral and I/V } \\
\text { antifungals, steroids }\end{array}$ & Mucormycosis \\
\hline 8 & $\begin{array}{l}\text { Extraaxial lesion, dural enhancement } \\
\text { and encasement of cavernous ICA }\end{array}$ & Meningioma & $\begin{array}{l}\text { Operated, I/V antifun- } \\
\text { gals }\end{array}$ & Aspergillosis \\
\hline 9 & $\begin{array}{l}\text { Right temporoparietal abscess with } \\
\text { peripheral and intrapapillary diffusion } \\
\text { restriction }\end{array}$ & - & $\begin{array}{l}\text { Operated, Oral and } \mathrm{I} / \mathrm{V} \\
\text { antifungals, steroids }\end{array}$ & Phaeohyphomycosis \\
\hline 10 & $\begin{array}{l}\text { Pachymeningitis with sub periosteal } \\
\text { abscess in right temporoparietal re- } \\
\text { gion with sphenoid sinusitis and bony } \\
\text { destruction }\end{array}$ & - & $\begin{array}{l}\text { Operated, I/V antifun- } \\
\text { gals, steroids }\end{array}$ & Mucormycosis \\
\hline
\end{tabular}

peripheral ring enhancement with mild central restriction and no significant restriction in the wall. Moreover in the case of cerebritis due to Penicillium sp there was evidence of patchy enhancement and restriction. (Figures $1 \mathrm{c}$ and $1 \mathrm{~d}$ ) Our findings match the spectrum described by Gaviani $\mathrm{P}$ et $\mathrm{al}^{4}$ who opined that fungal abcess can present as cerebritis with heterogeneous foci of restricted diffusion or central restricted diffusion similar to that of bacterial abscesses.

In our study, one case was of oculo-rhino-cerebral mucormycosis with associated osteomyelitis of the sphenoid and right temporal bone. (Figure 2)

Bone destructing property of mucormycosis is well known. Addlestone and Baylin ${ }^{5}$ concluded mucormycosis should be suspected in diabetics with destruction of the walls of the bony sinuses, especially when multiple sinuses are involved.

The other case of rhinocerebral mucormycosis in our study presented with sinusitis with intracranial bleed with subdural haemorrhage. (Figure 5)

Diabetics comprise $70 \%$ of the reported cases of mucormycosis with rhinocerebral form being the most common. Invasion of vessels causes thrombosis and hemorrhages. ${ }^{6}$

Two cases of cryptococcosis were encountered in our study. The first case showed neuroimaging features of meningitis and infarcts in the bilateral cerebral hemispheres. Chen et $\mathrm{al}^{7}$ in their study found acute/subacute cerebral infarction (ASCI) in $18.9 \%$ (7/37) of HIV-negative patients of cryptococcal meningitis. Gillams et a $1^{8}$ reviewed 71 abnormal cranial MR studies in human immunodeficiency virus (HIV)-positive patients with cryptococcosis. They reported infarcts in the basal ganglia area, the middle cerebral artery territory, and the vertebrobasilar territory.

The second case of cryptococcosis in our study was of a HIVpositive patient, in whom imaging revealed cryptococcal meningoencephalitis with hyperintense lesions in the basal ganglia.(Figure 4) Our findings match the imaging findings of Mathews et $\mathrm{al}^{9}$ who described punctate hyperintensities in the basal ganglia in patients with cryptococcosis. They described that these hyperintense lesions correspond pathologically to both perivascular spaces dilated by cryptococcal infection and cryptococcomas. Pathologically, cryptococcomas were more common than dilated perivascular spaces. ${ }^{7}$

Three atypical and rare cases of intracerebral fungal involvement were seen.

First was a case of 32 year female who presented with an extra axial lesion with peripheral and dural enhancement encasing the flow void of intracavernous part of right internal carotid artery (ICA) mimicking a meningioma. (Figure 5) Histopathological analysis revealed necrotic areas and giant cells with branching septate fungal hyphae of Aspergillus.

We could find only two similar case reports in literature. Banuprakash et $\mathrm{al}^{10}$ in 2009 described a mass lesion in the right sphenoid wing with conventional imaging findings 
that were typical of meningioma. Periodic acid Schiff staining revealed segmented hyphae. Mycological culture and microscopy revealed the presence of Aspergillus flavus in the lesion.

Another similar case has also been reported by Gupta et $\mathrm{a}^{11}$ who reported a case of intracranial granuloma caused by Aspergillus fumigatus involving the anterior cranial fossa whose appearance simulated that of a meningioma.

Our second atypical case was that of a giant aspergilloma mimicking butterfly glioma. The patient was mentally retarded, with new onset excessive drowsiness. Neuroimaging revealed a large heterogeneously enhancing lesion involving the corpus callosum, extending across the midline with significant mass effect. (Figure 6) We couldn't find any case report in literature with similar imaging findings till date. The closest we could find was the report of a syphilitic gumma mimicking a glioblastoma multiforme. ${ }^{12}$

Our third atypical case was that of a 35 year female, a known case of lupus with lupus nephritis. She had episodes of fever and presented in status. Non contrast MR brain revealed a well-marginated lesion with T2 hypointense rim and internal projections in the right temporal region. Diffusion restriction was seen at the periphery of the lesion and in the internal projections. Blooming suggestive of hemorrhage was seen on gradient recalled echo imaging [GRE]. Per operative findings revealed thick abscess capsule with approximately $15 \mathrm{ml}$ of dirty-yellow pus that was aspirated. Histopathology revealed areas of inflammation interspersed with brown coloured spores and septate fungal hyphae- cerebral phaeohyphomycosis. Very few case reports exist describing this entity. ${ }^{13-15}$

Nóbrega et al ${ }^{16}$ reported the first human culture-proven case of brain abscesses due to Fonsecaea pedrosoi, a dematiaceous fungi. The patient, a 28 year-old immunocompetent white male, whose MRI of the brain revealed a main tumoral mass involving the right temporo-occipital area and another smaller apparently healed lesion at the left occipital lobe. A cerebral biopsy proved cerebral chromoblastomycosis.

\section{CONCLUSION}

We diagnosed 10 cases with intracranial fungal infections with female: male ratio of 3:7. The age group of the patients ranged from 24 to 65 years with a median age of 45 years. Most of the patients had either an underlying history of immunosuppression or fungal sinusitis which predisposed to the rhino cerebral infection. Head ache was the most common symptom present in 6 patients (60\%).

The GCS score of the patients ranged from 15 to 10 with a median score of 14. Associated sinusitis and / or orbital pathology were present in half of the patients.

On reviewing the neuroimaging, we concluded that Immunosuppression in any form is a risk factor for fungal infection of the central nervous system.

Fungal cerebral abscesses may have central restricted diffusion, apart from the well-recognized abscess with restriction in the wall and intrapillary projections.

Oculo-rhino-cerebral pathology with bone destruction usually has fungal etiology.

Cerebral infarcts in immunocompromised, with or without significant meningeal enhancement, may be due to cryptococcosis.

Aspergillosis (fungal) may manifest as an extradural lesion mimicking a meningioma.

\section{REFERENCES}

1. Khandelwal N, Gupta V, Singh P. Central nervous system fungal infections in tropics. Neuroimaging Clin N Am. 2011; 21(1):859-66.

2. Sethi PK, Khanna L, Batra A, Anand I, Sethi NK, Torgovnick J, et al. Central nervous system fungal infections: Observations from a large tertiary hospital in northern India. Clin Neurol Neurosurg 2012;114 (3):1232-7.

3. Luthra G, Parihar A, Nath K, Jaiswal S, Prasad KN, Husain N. Comparative evaluation of fungal, tubercular, and pyogenic brain abscesses with conventional and diffusion MR imaging and proton MR spectroscopy. AJNR Am J Neuroradiol. 2007;28 (5):1332-8.

4. Gaviani P, Schwartz RB, Hedley-Whyte ET, Ligon KL, Robicsek A, Schaefer P. Diffusion-weighted imaging of fungal cerebral infection. AJNR Am J Neuroradiol. 2005;26 (1):1115-21.

5. Addlestone RB, Baylin GJ. Rhinocerebral mucormycosis. Radiology. 1975;115 (6):113-7.

6. Jain KK, Mittal SK, Kumar S, Gupta RK. Imaging features of central nervous system fungal infections. Neurol India 2007;55 (5):241-50.

7. Chen SF, Lu CH, Lui CC, Huang CR, Chuang YC, Tan TY. Acute/subacute cerebral infarction (ASCI) in HIVnegative adults with cryptococcal meningoencephalitis (CM): a MRI-based follow-up study and a clinical comparison to HIV-negative CM adults without ASCI. BMC Neurol. 2011; 26 (3);11:12.

8. Gillams AR, Allen E, Hrieb K, Venna N, Craven D, Carter AP. Cerebral infarction in patients with AIDS. AJNR Am J Neuroradiol. 1997;18(8):1581-5.

9. Mathews VP, Alo PL, Glass JD, et al. AIDS-related CNS cryptococcosis: Radiologic-pathologic correlation. AJNR Am J Neuroradiol 1992;13 (1):1477-1486.

10. Banuprakash S, Jolappara M, Kesavadas C, Saini J, Rao RM, Radhakrishnan VV. Atypical fungal granuloma of the sphenoid wing. J Neuroradiol. 2009;36(4):233-6.

11. Gupta R, Singh AK, Bishnu P, Malhotra V. Intracranial Aspergillus granuloma simulating meningioma on MR imaging. J Comput Assist Tomogr.1990;14 (6):467-9.

12. Ances BM, Danish SF, Kolson DL, Judy KD, Liebeskind DS. Cerebral gumma mimicking glioblastoma multiforme. Neurocrit Care. 2005;2 (5):300-2.

13. Salem FA, Kannangara DW, Nachum R. Cerebral chromomycosis. Arch Neurol. 1983;40 (4):173-4.

14. Li DM, de Hoog GS. Cerebral phaeohyphomycosis- A cure at what lengths? Lancet Infect Dis. 2009;9:376-83.

15. Nishitani H, Nishitani K, Numaguchi Y, Honbo S. Cerebral chromomycosis. J Comput Assist Tomogr. 1982;6 (2):624-6.

16. Nóbrega JP, Rosemberg S, Adami AM, Heins-Vaccari EM, Lacaz Cda S, de Brito T. Fonsecaea pedrosoi cerebral phaeohyphomycosis ("chromoblastomycosis"): first human culture-proven case reported in Brazil. Rev Inst Trop Sao Paulo 2003;45 (8):217-20.

Source of Support: Nil; Conflict of Interest: None

Submitted: 05-05-2018; Accepted: 04-06-2018; Published online: 15-06-2018 